\title{
A novel pathway for mineralization of the thiocarbamate herbicide molinate by a defined bacterial mixed culture
}

\author{
Luísa Barreiros, ${ }^{1,2}$ Balbina Nogales, ${ }^{3,4}$ \\ Célia M. Manaia, ${ }^{2}$ António C. Silva Ferreira, ${ }^{2}$ \\ Dietmar H. Pieper, ${ }^{3}$ Maria A. Reis, ${ }^{5}$ and \\ Olga C. Nunes ${ }^{1 *}$ \\ ${ }^{1}$ LEPAE - Departamento de Engenharia Química, \\ Faculdade de Engenharia, Universidade do Porto, Porto, \\ Portugal. \\ ${ }^{2}$ Escola Superior de Biotecnologia, Universidade Católica \\ Portuguesa, 4200-072 Porto, Portugal. \\ ${ }^{3}$ Division of Microbiology, GBF-German Research Centre \\ for Biotechnology, Braunschweig, Germany. \\ ${ }^{4}$ Area de Microbiologia, Universitat de les Illes Balears, \\ Palma de Mallorca, Spain. \\ ${ }^{5}$ Department of Chemistry, Faculdade de Ciências e \\ Tecnologia, Universidade Nova de Lisboa, Monte da \\ Caparica, Portugal.
}

\section{Summary}

A bacterial mixed culture able to mineralize molinate was established, through enrichment, using mineral medium with molinate as the only carbon, nitrogen and energy source. The combination of five cultivable isolates, purified from the enrichment culture, permitted the reconstitution of a degrading consortium. Both enrichment and defined cultures were able to mineralize molinate without accumulation of degradation products by the end of the growth. Among the five isolates constituting the defined mixed culture, an actinomycete, strain ON4, was essential for biodegradation, being involved in the cleavage of the thioester bond of molinate, the initial step of the degradation pathway. Isolate ON4 was able to grow on molinate at concentrations below $2 \mathrm{mM}$, with the accumulation of ethanethiol and diethyl disulphide. These sulphur compounds were toxic to strain ON4 when accumulating at higher concentrations. However, this inhibitory effect was avoided by the presence of other members of the mixed culture, out of which isolates ON1 and ON2 were observed to consume ethanethiol and diethyl disulphide. In this way, interactions among defined mixed culture members involve metabolic and detoxifying association.

\author{
Introduction
}

Molinate (S-ethyl perhydroazepine-1-carbothioate) is a systemic thiocarbamate herbicide used world-wide to control weeds in rice paddies. Molinate is applied to flooded fields, and due to the flow of water between the fields and surroundings, contamination of receiving waters has occurred in various countries at levels up to $100 \mathrm{\mu g} \mathrm{I}^{-1}$ of the herbicide (Carrasco et al., 1987; Julli and Krassoi, 1995; Mabury et al., 1996). A review of the toxicological information of molinate indicates that this herbicide has adverse reproductive effects, is neurotoxic and possible oncogenic (Cochran et al., 1997).

According to literature, dissipation of molinate in fields is mainly due to volatilization (75-85\%), although photolysis (5-10\%), and adsorption and biodegradation (5$10 \%$ ) are also supposed to occur (Soderquist et al., 1977; Rajagopal et al., 1984; Mabury et al., 1996).

Although molinate is considered one of the most recalcitrant thiocarbamates (Nagy et al., 1995), several soil and water microorganisms, both in mixed populations or in pure cultures (fungi and bacteria), have been reported to convert molinate into partially oxidized products (Klysheva et al., 1980; Golovleva et al., 1981; Zyakun et al., 1983; Imai and Kuwatsuka, 1986a,b,c). Three main pathways have been proposed, based on products detected in molinate transforming microbial cultures, experimental soils and environmental samples (Soderquist et al., 1977; Thomas and Holt, 1980; Golovleva et al., 1981; Imai and Kuwatsuka, 1982). The oxidation of the ethyl moiety leads to the production of molinate alcohol and molinate acid, whereas hydroxy- and oxomolinate are derived from azepine ring oxidation. Molinate sulphoxide and sulphone are formed as a consequence of sulphur oxidation, and it is supposed that such a chemical modification may lead to the release of hexamethyleneimine ( $\mathrm{HMI})$. The degradation of molinate and its oxidized derivatives, namely with regard to the enzymes/catalysts involved, is not understood. Molinate sulphoxide seems to be a widespread oxidation product of molinate, being produced by eukaryotic cells (Jewell et al., 1999) or by chemical processes such as the chlorination employed in water treatment facilities (Cochran et al., 1997). Molinate sulphoxide has been reported as being more persistent and, above all, more toxic to animals than molinate (Golovleva et al., 1981; Ellis et al., 1998; Jewell and Miller, 1998; Tjeerdema and Crosby, 
1988; Jewell et al., 1999). Because molinate oxidation is thought to occur extensively, the contamination of natural waters with this herbicide may have more malignant effects than previously assumed.

This report describes a mixed bacterial culture able to mineralize molinate while using it as the only source of carbon, energy and nitrogen. Under these conditions, the defined mixed culture promoted molinate degradation without accumulation of dead-end products. Among the five cultivable bacterial isolates composing the defined mixed culture, an actinomycete was the only one capable of molinate transformation, in axenic culture.

\section{Results}

\section{Enrichment and characterization of molinate degrading cultures}

An enrichment culture was obtained, using molinate as carbon source, from a sample of sediment collected from a site where a molinate containing effluent has been discharged for several years. This enrichment culture, named EC1, reduced $400 \mathrm{mg} \mathrm{l}^{-1}$ of molinate to concentrations below the HPLC detection limit $\left(0.9 \mathrm{mg} \mathrm{l}^{-1}\right)$, with a specific degradation rate of $110 \mathrm{mg}$ of molinate $\mathrm{g}^{-1}$ (cells dry weight) $\mathrm{h}^{-1}$ and with a maximum specific growth rate of $0.04 \mathrm{~h}^{-1}$. High performance liquid chromatography (HPLC) analyses gave no indication for the accumulation of intermediates or dead-end products. The analysis of the microbial composition of consortium EC1 revealed the presence of at least 45 cultivable bacterial isolates, distinguishable by their colony morphology on PCA plates. In order to obtain a culture comprising a limited number of bacteria, together capable of molinate degradation, consortium EC1 was subcultured in medium containing molinate as single carbon and nitrogen source. Furthermore, a molinate concentration of $750 \mathrm{mg} \mathrm{l}^{-1}$, close to its maximum solubility, was used such that the selected microorganisms should be able to tolerate high concentrations of the herbicide. Plating of the thereby obtained enrichment culture (EC2) revealed the presence of five different morphological types of colonies. The respective colonies were purified and the isolates designated by isolate ON1 to ON5. None of the isolates was able to grow with $750 \mathrm{mg} \mathrm{l}^{-1}$ molinate as a single source of carbon and nitrogen in axenic culture. However, the artificial five-membered mixed culture consisting of the mixture of equal proportions of purified cultivable isolates from enrichment culture EC2 was able to grow on and to mineralize molinate. This defined mixed culture was named DC (defined culture). It could, thus, be concluded that, enrichment culture EC2 was at least composed by the five isolates and that they had a major role in molinate degradation.
Characterization of members of the defined mixed culture DC

Isolates ON1 to ON5 were characterized using FAMEs profiling, Biolog assays and 16S rDNA sequencing analysis. Out of the five isolates, only ON4 was Gram-positive. The combination of the three employed methodologies permitted the identification of the Gram-negative isolates (ON1, ON2, ON3 and ON5), at least to the genus level. Their 16S rDNA sequences presented high percentage of identity (above 99\%) with reference 16S rDNA sequences in the EMBL database. Biolog and GC-FAME coefficients for these isolates were above the minimal matches values referred in guidelines of these systems ( 0.5 and 0.3 respectively). Isolates $\mathrm{ON} 1$ and $\mathrm{ON} 3$ were identified as members of the genus Pseudomonas, with similarities of $99.84 \%$ with the $16 \mathrm{~S}$ rRNA sequence of $P$. chlororaphis IFO $3904^{\top}$ and of $99.77 \%$ with $P$. nitroreducens IAM $1439^{\top}$ respectively. The 16S rRNA sequence of isolate ON5 had 99.60\% similarity with that of Achromobacter xylosoxidans ssp. denitrificans ATCC $15173^{\top}$. Isolate ON2 was identified as Stenotrophomonas maltophilia showing a similarity of $99.32 \%$ with S. maltophilia ATCC $15173^{\top}$. The fifth isolate, ON4 was a Gram-positive bacterium, affiliated by 16S rDNA sequence analysis to the actinomycetes with peptidoglycan Group B (Rainey et al., 1994), being Curtobacterium flaccumfaciens pv. flaccumfaciens LMG $3645^{\top}$ the closest validly described species $(95.30 \%$ similarity).

Degradation of molinate by enrichment culture EC2 and defined mixed culture $D C$

Both, the enrichment culture EC2 and the defined mixed culture DC were able to grow and mineralize molinate when grown with concentrations up to $750 \mathrm{mg} \mathrm{l}^{-1}$ of the herbicide. For both mixed cultures, the association between cell growth and molinate depletion was evidenced by the fact that the exponential growth phase was coincident with molinate consumption, and growth ceased after molinate had been consumed (Fig. 1A and B). There was a direct association between the total organic carbon of the culture supernatants (referred as dissolved organic carbon, DOC) and molinate depletion by both cultures; DOC contents decreased by more than $91 \%$ when cultures were grown with molinate as the sole source of carbon and nitrogen (Table 1). No degradation of molinate was observed in uninoculated controls. Both cultures EC2 and DC were able to degrade molinate to concentrations below the detection limit, and the maximum specific growth and molinate degradation rates of defined mixed culture DC $\left[0.081 \pm 0.01 \mathrm{~h}^{-1}\right.$ and $189.4 \pm 18.9 \mathrm{mg}$ of molinate $\mathrm{g}^{-1}$ (cells dry weight) $\mathrm{h}^{-1}$, respectively] were slightly higher than those of enrichment culture EC2 $\left[0.073 \pm 0.01 \mathrm{~h}^{-1}\right.$ 

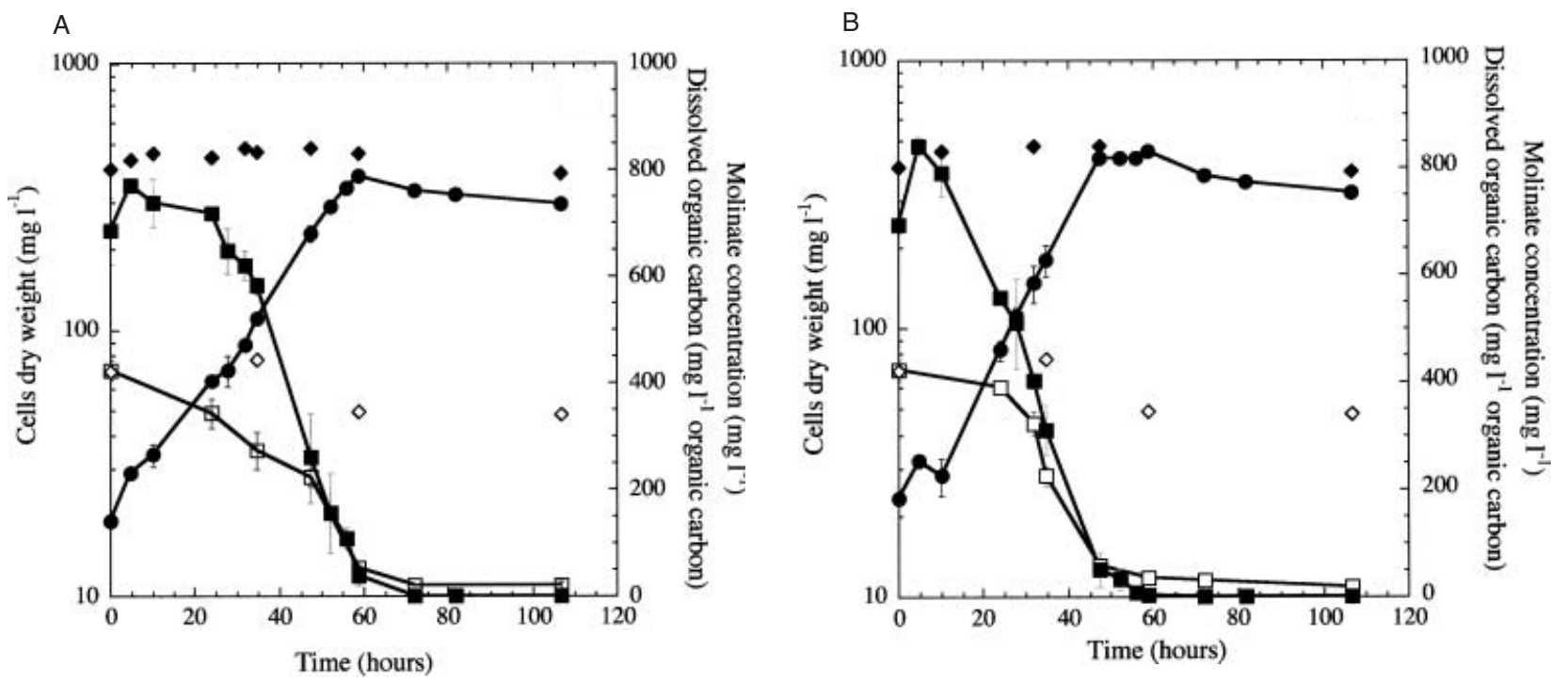

Fig. 1. Enrichment culture EC2 (A) and defined mixed culture DC (B) grown in medium B with $750 \mathrm{mg} \mathrm{l}^{-1}$ molinate. Symbols: $\mathbf{\square}$, Molinate concentration $\left(\mathrm{mg} \mathrm{l}^{-1}\right)$ in culture supernatant. Molinate concentration in uninoculated control. $\bullet$, Growth curve. $\square$, Dissolved organic carbon ( $\mathrm{mg} \mathrm{l}^{-1}$ organic carbon) in culture supernatant. $\diamond$, Dissolved organic carbon in uninoculated control. The values are the means of three independent experiments, and the error bars show standard deviations.

and $133.8 \pm 9.8 \mathrm{mg}$ of molinate $\mathrm{g}^{-1}$ (cells dry weight) $\mathrm{h}^{-1}$, respectively]. Resting cells analyses confirmed that both cultures, EC2 and DC, exhibited similar molinate degradation rates of 119 and $122 \mathrm{mg}$ of molinate $\mathrm{g}^{-1}$ (cells dry weight) $\mathrm{h}^{-1}$ respectively.

Solid-phase micro extraction followed by gas chromatography analysis (SPME/GC) methodology revealed that molinate solutions (Herbex) contained impurities (Fig. 2A). Two of the contaminating compounds were identified as ethanethiol, and diethyl disulphide by comparison of retention time and MS spectra with those of authentic standards, and each of these compounds represented less than $5 \%$ of the compound mixture. Two further compounds were tentatively identified, by comparing the Kovats indices and the mass spectra present in the NIST 98 MS Library Database, as diethyl trisulphide and S,S-diethyl ester carbonodithioic acid respectively. No changes were observed when uninoculated medium with molinate was incubated. As is shown in Fig. 2D, defined mixed culture DC was not only capable to degrade molinate but also to degrade impurities present in the medium, as evidenced by the disappearance of the respective GC signals during growth.

\section{Role of isolates in the degradation of molinate}

As mentioned above, none of the five isolates (ON1-ON5) was able to grow in pure cultures in medium $B$ with $750 \mathrm{mg} \mathrm{l}^{-1}$ molinate as the only source of carbon, nitrogen and energy or even in the presence of ammonia as additional nitrogen source. All isolates were further tested for their capability to transform molinate as single source of carbon and nitrogen and in the presence of other carbon sources (yeast extract). None of the Gram-negative isolates was able to grow or degrade the herbicide in axenic culture at any molinate concentration tested, as the only source of carbon and nitrogen or when the medium was supplemented with $0.1 \%(\mathrm{wt} / \mathrm{vol})$ yeast extract. Resting cells assays with individual Gram-negative isolates confirmed that they were unable of molinate transformation. In contrast, isolate ON4 was able, in pure culture, to grow with molinate as the sole nutrient, producing biomass when the substrate was supplied at low concentrations $(\leq 2 \mathrm{mM})$ and reducing the herbicide to undetectable levels (Table 1). However, growth ceased after successive transfers in medium B with $187 \mathrm{mg} \mathrm{l}^{-1}$ molinate, suggesting that reserve materials might be used as growth factors. In fact, good growth was observed in medium B with $187 \mathrm{mg} \mathrm{I}^{-1}$ molinate supplemented with $0.02 \%$ (wt/vol) of yeast extract, suggesting that unknown growth requirements may be involved. These results also may indicate that growth requirements can be fulfilled by other isolates when isolate ON4 is growing in defined mixed culture DC. The molinate degradation rate by resting cells of isolate ON4 [111 mg of molinate $\mathrm{g}^{-1}$ (cells dry weight) $\mathrm{h}^{-1}$ ] was similar to those obtained for cultures EC2 and DC [119 and $122 \mathrm{mg}$ of molinate $\mathrm{g}^{-1}$ (cells dry weight) $\mathrm{h}^{-1}$, respectively], which suggests that isolate ON4 might be important for the whole degradation process.

No growth occurred when isolate ON4 was inoculated in medium with higher concentrations of molinate (Table 1), neither when this medium was supplemented with $0.1 \%(\mathrm{wt} / \mathrm{vol})$ of yeast extract, in sealed vials. How- 
Table 1. Molinate degradation by enrichment culture EC2 and defined mixed culture DC and isolate ON4 with different herbicide concentrations.

\begin{tabular}{|c|c|c|c|c|c|c|c|c|c|c|c|c|}
\hline & \multicolumn{6}{|c|}{ Cultures in medium B with $187 \mathrm{mg} \mathrm{I}^{-1}$ molinate } & \multicolumn{6}{|c|}{ Cultures in medium B with $750 \mathrm{mg} \mathrm{I}^{-1}$ molinate } \\
\hline & \multicolumn{2}{|c|}{$\begin{array}{l}\text { Cells dry } \\
\text { weight } \\
\left(\mathrm{mg} \mathrm{l}^{-1}\right)\end{array}$} & \multicolumn{2}{|c|}{$\begin{array}{l}\text { Molinate } \\
\left(\mathrm{mg} \mathrm{I}^{-1}\right)\end{array}$} & \multicolumn{2}{|c|}{$\mathrm{DOC}\left(\mathrm{mg} \mathrm{l}^{-1}\right)$} & \multicolumn{2}{|c|}{$\begin{array}{l}\text { Cells dry } \\
\text { weight } \\
\left(\mathrm{mg} \mathrm{l}^{-1}\right)\end{array}$} & \multicolumn{2}{|c|}{$\begin{array}{l}\text { Molinate } \\
\left(\mathrm{mg} \mathrm{I}^{-1}\right)\end{array}$} & \multicolumn{2}{|c|}{$\mathrm{DOC}\left(\mathrm{mg} \mathrm{I}^{-1}\right)$} \\
\hline & $0 \mathrm{~d}$ & $5 d$ & $0 \mathrm{~d}$ & $5 d$ & $0 \mathrm{~d}$ & $5 \mathrm{~d}$ & $0 \mathrm{~d}$ & $5 d$ & $0 \mathrm{~d}$ & $5 \mathrm{~d}$ & $0 \mathrm{~d}$ & $5 d$ \\
\hline Consortium EC2 & 50 & 100 & 170 & $<0.9$ & 90 & 10 & 20 & 300 & 690 & $<0.9$ & 420 & 20 \\
\hline Consortium DC & 50 & 130 & 180 & $<0.9$ & 100 & 10 & 20 & 320 & 690 & $<0.9$ & 420 & 20 \\
\hline Isolate ON4 & 30 & 120 & 190 & $<0.9$ & 105 & 20 & 30 & 25 & 700 & 260 & 450 & 180 \\
\hline Gram-negative isolates & 40 & 20 & 190 & 190 & 100 & 105 & - & - & - & - & - & - \\
\hline Abiotic control & - & - & 200 & 210 & 100 & 110 & - & - & 800 & 790 & 420 & 340 \\
\hline
\end{tabular}

Values are means of at least two independent experiments. HPLC detection limit of $0.9 \mathrm{mg} \mathrm{l}^{-1}$. $\mathrm{d}$, days.

ever, significant molinate transformation was observed. These results suggest that an inhibitory effect due to the presence of high concentrations of molinate degradation products was taking place (see below).

Previous studies on molinate (bio)degradation have detected molinate derivatives, such as sulphoxide and sulphone, oxo- and hydroxy-, and alcohol and acid (Soderquist et al., 1977; Klysheva et al., 1980; Golovleva et al., 1981; Imai and Kuwatsuka, 1982; 1986a,b,c; Zyakun et al., 1983; Cochran et al., 1997) as dead-end metabolites. The occurrence of some of these products during biological degradation of molinate by defined mixed culture DC and isolate ON4 was investigated using organic extracts of supernatants obtained from growing cultures as described by Imai and Kuwatsuka (1982). The extracts were analysed by HPLC and GC/FID and com-
Retention time (min)

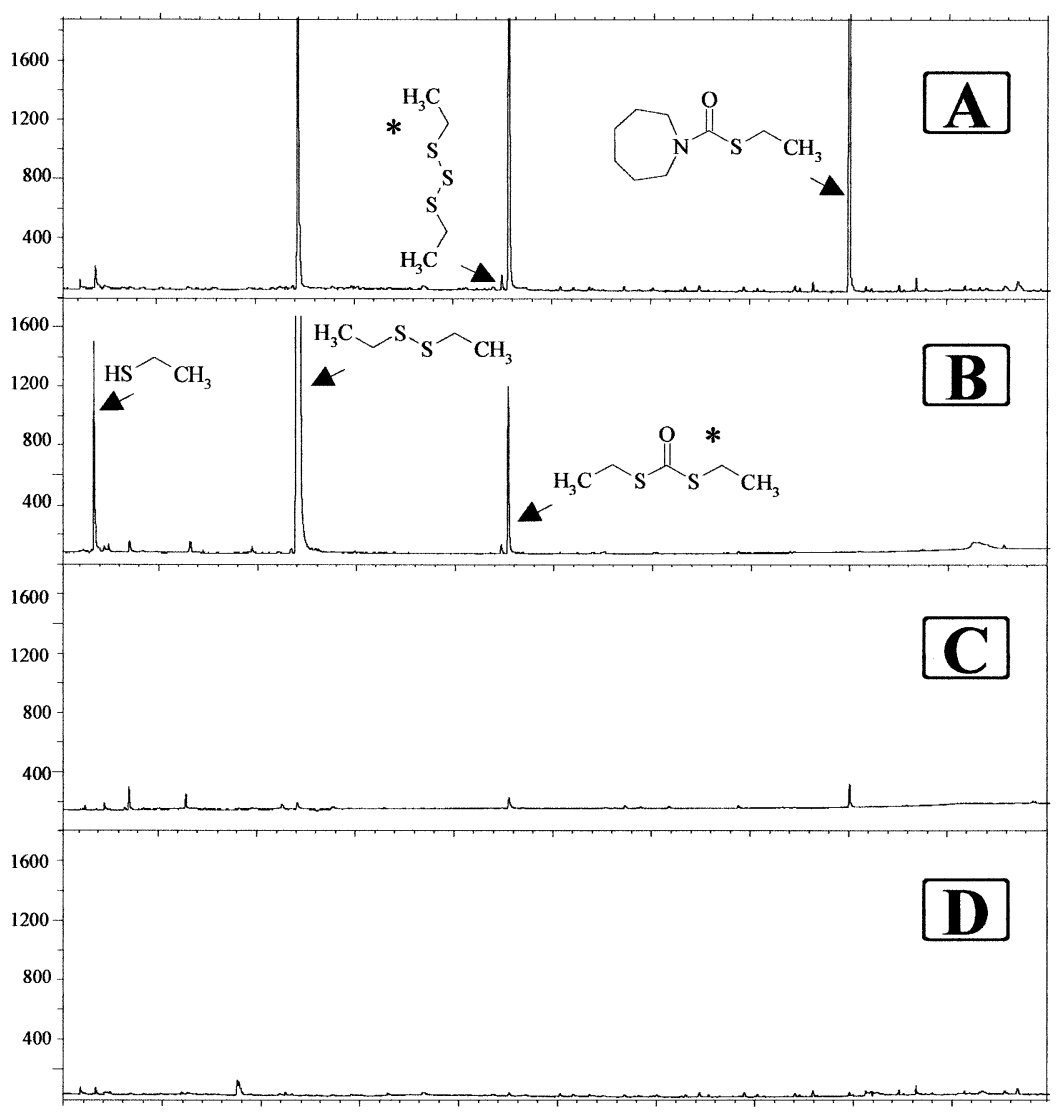

Fig. 2. Chromatograms obtained by SPME/GC/ FID analysis of headspace of different cultures in medium $B$ with $187 \mathrm{mg} \mathrm{l}^{-1}$ molinate. Uninoculated medium after 7 days of incubation $(A)$. Culture of isolate ON4 after 7 days of incubation (B). Culture of isolate ON4 with a mixed culture of the Gram-negative isolates incubated in a vial placed in the headspace, after 7 days of incubation (C). Culture of defined mixed culture DC after 7 days of incubation (D). $\left(^{*}\right)$ Tentatively identified by comparing the Kovats indices and the mass spectra present in the NIST 98 MS Library Database. Retention time of the compounds: ethanethiol, $3.2 \mathrm{~min}$; diethyl disulphide, $24 \mathrm{~min}$; diethyl trisulphide, $44 \mathrm{~min}$; $\mathrm{S}$,S-diethyl ester carbonodithioic acid, $45 \mathrm{~min}$; and molinate, $80 \mathrm{~min}$.

Retention Index 
pared with authentic standards of molinate sulphoxide, molinate sulphone, 2-oxo-molinate, molinate acid and molinate alcohol. None of these compounds were detected after molinate degradation by cultures of defined mixed culture DC or of isolate ON4.

Semiquantitative SPME/GC analysis of cultures and resting cell suspensions of isolate ON4, revealed that the disappearance of molinate was concomitant with the increase in concentration of ethanethiol and diethyl disulphide. Although ethanethiol and diethyl disulphide were present in molinate solutions, the levels of these compounds clearly increased due to the activity of isolate ON4 (Fig. 2B). In fact, during molinate (1 mM) degradation, concentrations of ethanethiol and diethyl disulphide consistently increased 20 to 30 -fold (corresponding to approximately $1 \mathrm{mM}$ ) whereas for abiotic controls no significant changes were observed. These results suggested that isolate ON4 was able to cleave the thioester bond of molinate, releasing ethanethiol that would be further spontaneously oxidized to diethyl disulphide (see below).

The DOC values found after degradation of $1 \mathrm{mM}$ molinate by isolate ON4 were low (average of $20 \mathrm{mg} \mathrm{l}^{-1}$ ) and comparable to those determined for a $1 \mathrm{mM}$ solution of ethanethiol (average of $22 \mathrm{mgl}^{-1}$ ). These results suggested that isolate ON4 was able to mineralize the azepine moiety of molinate, but not the ethyl moiety.

As ethanethiol and diethyl disulphide were not present after growth of the defined mixed culture DC, which contained all the five isolates (see Fig. 2D for a comparison), the role of the Gram-negative isolates (ON1-ON3, and ON5) was analysed. The reconstitution of defined mixed culture DC by the addition of a mixture of resting cells of the Gram-negative members to cultures or resting cells of isolate ON4 preincubated with molinate, resulted in the degradation of these sulphur compounds (results not shown). In the same way, when a mixed culture of the Gram-negative isolates was incubated in a separated compartment of the flask containing a culture of isolate
ON4, the Gram-negative isolates were capable to use volatile hydrocarbons from the headspace and no products were accumulated during growth (Fig. 2C). Thus, these results indicate that defined mixed culture members other than isolate ON4 were responsible for degrading ethanethiol released from molinate by isolate ON4. In accordance with the assumption that high concentrations of ethanethiol might be toxic to isolate ON4, this organism was able to grow on $4 \mathrm{mM}$ molinate, when a mixed culture of the Gram-negative isolates was present in a separate compartment of the same flask (Table 2). These results prove the ability of the Gram-negative isolates to grow while consuming the metabolites produced by isolate ON4, therefore indicating the co-operative nature of the degradation of molinate between isolate ON4 and the Gram-negative isolates.

In order to evaluate which of the Gram-negative isolates were involved in the depletion of sulphur compounds, each individual isolate was incubated in medium B supplemented with $2.5 \mathrm{mM}$ ethanethiol and ammonium sulphate. According to SPME/GC analysis of the headspace of axenic cultures, only isolates ON1 and ON2 could degrade that sulphur compound among the individual members of defined mixed culture DC. However, ethanethiol was spontaneously converted to diethyl disulphide during the incubation period. In fact, in uninoculated medium with ethanethiol, half of its initial concentration was converted to diethyl disulphide within 4 days. Because the spontaneous conversion of ethanethiol to diethyl disulphide was not quantitative, but quantitative depletion was observed in the presence of isolates ON1 or ON2, it can be concluded that ethanethiol is transformed by those organisms. Moreover, both organisms are also capable of transforming diethyl disulphide.

The analytical methods utilised for liquid phase analysis (HPLC and CG/FID) of cultures or resting cells of isolate ON4 did not permit the detection of the azepine ring of molinate or its by-products. Hexamethyleneimine (HMI),

Table 2. Growth of isolate ON4 on $750 \mathrm{mg} \mathrm{l}^{-1}$ molinate and of a mixed culture of Gram-negative isolates incubated in a vial placed in the headspace of the culture of isolate ON4.

\begin{tabular}{|c|c|c|c|c|}
\hline \multirow[b]{2}{*}{ Incubation conditions } & \multicolumn{2}{|c|}{$\begin{array}{l}\text { Cells dry weight of isolate ON4 } \\
\left(\mathrm{mg} \mathrm{l}^{-1}\right)\end{array}$} & \multicolumn{2}{|c|}{$\begin{array}{l}\text { Cells dry weight of } \\
\text { Gram-negative isolates }\left(\mathrm{mg} \mathrm{l}^{-1}\right)\end{array}$} \\
\hline & 0 days & 10 days & 0 days & 10 days \\
\hline $\begin{array}{l}\text { Bottom: Culture of isolate ON4 in medium B with } 750 \mathrm{mg} \mathrm{l}^{-1} \text { molinate. } \\
\text { Headspace: Culture of Gram-negative isolates in medium B with }\left(\mathrm{NH}_{4}\right)_{2} \mathrm{SO}_{4} \text {. }\end{array}$ & 40 & 140 & 40 & 110 \\
\hline $\begin{array}{l}\text { Bottom: Medium B with } 750 \mathrm{mg} \mathrm{I}^{-1} \text { molinate. } \\
\text { Headspace: Culture of Gram-negative isolates in medium B with }\left(\mathrm{NH}_{4}\right)_{2} \mathrm{SO}_{4} \text {. }\end{array}$ & Not applicable & Not applicable & 40 & 50 \\
\hline $\begin{array}{l}\text { Bottom: Culture of isolate ON4 in medium B without molinate. } \\
\text { Headspace: Culture of Gram-negative isolates in medium B with }\left(\mathrm{NH}_{4}\right)_{2} \mathrm{SO}_{4} \text {. }\end{array}$ & 40 & 20 & 40 & 60 \\
\hline $\begin{array}{l}\text { Bottom: Culture of isolate } \mathrm{ON} 4 \text { in medium } \mathrm{B} \text { with } 750 \mathrm{mg} \mathrm{l}^{-1} \text { molinate. } \\
\text { Headspace: Medium with }\left(\mathrm{NH}_{4}\right)_{2} \mathrm{SO} 4 .\end{array}$ & 40 & 50 & Not applicable & Not applicable \\
\hline
\end{tabular}

Values are means of two independent experiments. 
an analogue compound of molinate, has been referred in the literature as a possible product of molinate degradation (Thomas and Holt, 1980; Imai and Kuwatsuka, 1982; 1986c). In this way, it was tested if the individual members of the defined mixed culture DC could grow in medium B with $2.5 \mathrm{mM} \mathrm{HMI}$. Under these conditions, only the Pseudomonas spp. isolates ON1 and ON3 were able to grow in axenic culture on $\mathrm{HMI}$ as carbon and nitrogen source. Because $\mathrm{HMI}$ could not support growth of isolate ON4, whereas this organism could grow on $187 \mathrm{mg} \mathrm{l}^{-1}$ molinate with the accumulation of sulphur compounds (see above), it seems improbable that HMl is an intermediate of molinate degradation by this organism.

\section{Discussion}

The majority of published studies on molinate biodegradation show that the transformation of this herbicide takes place only in the presence of other carbon sources (Klysheva et al., 1980; Golovleva et al., 1981; Imai and Kuwatsuka, 1982; 1986a,b; Molinari et al., 1992; Daffonchio et al., 1996; Daffonchio et al., 1999), leading to the accumulation of partially oxidized products (Klysheva et al., 1980; Golovleva et al., 1981; Zyakun et al., 1983; Imai and Kuwatsuka, 1986a,b,c). The only exception is the work reported by Carrasco et al. (1992) with a mixed microbial culture that was able to degrade $50 \mathrm{mg} \mathrm{l}^{-1}$ molinate, as the only carbon source, in a continuous flow reactor fed with mineral medium with ammonia as nitrogen source. Carrasco et al. (1992) reported a molinate depletion of about $97 \%$ for a residence time of 23 days, and accumulation of metabolic products derived from molinate degradation were detected, although in trace amounts (12 p.p.b.). In this respect, the present work is innovative as the microbial cultures isolated were able to use molinate as the single source of carbon, nitrogen and energy. Moreover, when compared to other published reports (Klysheva et al., 1980; Golovleva et al., 1981; Imai and Kuwatsuka, 1982; 1986a,b,c; Carrasco et al., 1992; Daffonchio et al., 1996; Daffonchio et al., 1999), enrichment culture EC2 and defined mixed culture DC revealed an increased tolerance to molinate (c.a. seven times), and were able to reduce molinate to undetectable levels, accompanied by DOC depletion when grown with $750 \mathrm{mg} \mathrm{l}^{-1}$ molinate.

Although among the five individual isolates composing defined mixed culture DC only isolate ON4 was able to degrade the herbicide, it was not responsible for molinate mineralization. SPME/GC analysis revealed that the activity of isolate ON4 leads to the accumulation of ethanethiol and mainly diethyl disulphide in headspace of its cultures or resting cells. Although ethanethiol, along with other sulphur compounds, seems to be a contaminant of molinate itself, the increase in the levels of this thiol could be clearly attributed to the activity of isolate ON4. The production of ethanethiol was accompanied by the accumulation of diethyl disulphide, which might be the result of the spontaneous oxidation of ethanethiol. A similar description is made by Sipma et al. (2002) who reported the accumulation of dimethyl disulphide in an upflow anaerobic sludge-digestor during methanethiol degradation, due to the presence of minor amounts of oxygen. On the other hand, the inability of isolate ON4 to grow in axenic culture in the presence of $750 \mathrm{mg} \mathrm{l}^{-1}$ of molinate, was due to the accumulation of high concentrations of sulphur degradation products. It is reported in literature that polysulphide bounds, as di- or tri-sulphides, may retard or inhibit microbial growth (Kyung and Fleming, 1997; Tsao and Yin, 2001). In this respect, the intervention of Gram-negative isolates may be very important as detoxifying agents, as isolate ON4 was able to grow with $750 \mathrm{mg} \mathrm{l}^{-1}$ molinate when the remaining defined mixed culture members removed those compounds from headspace of its culture. In fact, it was observed that at least isolates ON1 and ON2 had the capability to consume such degradation products. These results suggests that a mixture of isolate ON4 with one of these isolates (ON1 or ON2) are enough to perform the herbicide mineralization. However, it was not possible, until now, to establish which mixed culture composition presents the maximal efficiency of molinate mineralization.

The requirement of a consortium to achieve molinate mineralization is not surprising, as combined metabolic activity of mixed bacterial communities seems to be rather common in degradation of pollutants. In general, three distinct types of co-operation may occur among bacterial consortia members during degradation of organic pollutants - metabolic deficiency, metabolic association and metabolite detoxification. In metabolic deficiency the degrading organism has specific nutritional requirements, necessary to promote or increase degradation, which are provided by secondary strains. Examples of this co-operative association are described by Hay et al. (2001), reporting the degradation of the antimicrobial triclosan or by Sorensen et al. (2002), on a study of degradation of the herbicide isoproturon. Metabolic association is characterized by the cross-feeding of metabolites from the degradation pathway within the consortium members. Eventually, this is the commonest form of co-operation, and numerous examples can be found (e.g. Arfmann et al., 1997; Chapalamadugu and Chaudhry, 1991; De Souza et al., 1998; Carvalho et al., 2002). Metabolite detoxification, which can be considered a particular case of metabolic association, involves the production of a toxic and/or inhibitory metabolite by the degrading organism and its consumption by secondary strains. Examples of this kind of co-operative association are described by Feigel and Knackmuss (1993), reporting the mineraliza- 
tion of 4-aminobenzenesulphonic acid, or Pelz et al. (1999) on a study about chlorosalicylate degradation. Although the interspecies interactions in defined mixed culture DC are not completely understood yet, it is clear that metabolic association and detoxification impose the interdependence between consortium DC members. However, the similarity of molinate degradation rates observed for isolate ON4 and for defined mixed culture DC suggests that isolate ON4, in mixed culture, is the first to attack molinate and probably the rate limiting member.

Although some authors have proposed that thiocarbamate oxides are precursors for biodegradation (Rajagopal et al., 1984; Imai and Kuwatsuka, 1982; 1986c), it was Nagy et al. (1995) who presented the first evidence for an oxidative metabolism of the herbicide EPTC (S-ethyl dipropylcarbamothioate), involving an inducible cytochrome P450. These authors found EPTC-sulphoxide as a degradation product, although did not conclude whether this compound constituted a dead-end metabolite. Because several thiocarbamates, but not molinate, could interact with that cytochrome P450, Nagy et al. (1995) concluded that this herbicide could not be degraded by such process. An alternative degradation process is described for EPTC, involving the hydrolysis of the thioester bound, with the release of ethanethiol, dipropilamine and $\mathrm{CO}_{2}$ (McClung et al., 1994).

The mechanism and catalysts used by isolate ON4 in molinate transformation are not characterized yet. However, attending to the results obtained throughout this study and considering the hypothesis of McClung et al. (1994) it is possible to propose a metabolic route for molinate degradation involving the hydrolysis of the thioesther bond by isolate ON4. Through this hydrolysis, isolate ON4 would originate ethanethiol and $\mathrm{N}$-carboxy hexamethyleneimine, supplying carbon and nitrogen sources for its own growth and for other consortium members. Future studies will focus on the characterization of this enzyme system of isolate ON4, which is responsible for the beginning of molinate mineralization by the defined mixed culture.

Defined mixed culture DC is robust and highly efficient in molinate mineralization and represents a valuable tool for decontamination of molinate polluted waters under field conditions. Further studies will contribute to better understand the contribution of each mixed culture member to promote and maximise the efficiency of molinate mineralization.

\section{Experimental procedures}

\section{Chemicals}

Molinate (S-ethyl perhydroazepine-1-carbothioate) of $99 \%$ purity was obtained from Riedel-de Haën (Seelze, Germany) and molinate of $97 \%$ purity from Herbex, Produtos Químicos (Estoril, Portugal). Molinate sulphoxide, molinate-sulphone, molinate-acid, molinate-alcohol and 2-oxo-molinate were purchased from Dr Ehrenstorfer GmbH (Augsburg, Germany). Ethanethiol, diethyl disulphide and hexamethyleneimine (HMI) were obtained from Sigma-Aldrich (Steinheim, Germany).

\section{Mineral media}

Two kinds of mineral media were used during this study. Medium A contained $\mathrm{Na}_{2} \mathrm{HPO}_{4}(6.0 \mathrm{mM}), \mathrm{KH}_{2} \mathrm{PO}_{4}(4.0 \mathrm{mM})$, $\mathrm{CaCl}_{2} \cdot \mathrm{H}_{2} \mathrm{O} \quad(0.47 \mathrm{mM}), \quad \mathrm{NaCl}(0.14 \mathrm{mM}), \quad \mathrm{MgSO}_{4} \cdot 7 \mathrm{H}_{2} \mathrm{O}$ $(0.41 \mathrm{mM})$, nitrilotriacetate $(0.52 \mathrm{mM}), \mathrm{FeSO}_{4} .7 \mathrm{H}_{2} \mathrm{O}(2 \mathrm{mg}$ $\left.\mathrm{I}^{-1}\right), \quad \mathrm{ZnSO}_{4} \cdot 7 \mathrm{H}_{2} \mathrm{O} \quad\left(0.1 \mathrm{mg} \mathrm{l}{ }^{-1}\right), \quad \mathrm{MnSO}_{4} \cdot \mathrm{H}_{2} \mathrm{O}\left(0.03 \mathrm{mg} \mathrm{l}^{-1}\right)$, $\mathrm{H}_{3} \mathrm{BO}_{3}\left(0.3 \mathrm{mg} \mathrm{l}^{-1}\right), \mathrm{CoSO}_{4} .7 \mathrm{H}_{2} \mathrm{O}\left(0.24 \mathrm{mg} \mathrm{l}^{-1}\right), \mathrm{CuSO}_{4} .5 \mathrm{H}_{2} \mathrm{O}$ $\left(0.01 \mathrm{mg} \mathrm{l}^{-1}\right), \quad \mathrm{NiSO}_{4} .7 \mathrm{H}_{2} \mathrm{O} \quad\left(0.02 \mathrm{mg} \mathrm{l}^{-1}\right), \quad \mathrm{NaMoO}_{4} .2 \mathrm{H}_{2} \mathrm{O}$ $\left(0.03 \mathrm{mg} \mathrm{l}^{-1}\right), \mathrm{Ca}(\mathrm{OH})_{2}\left(0.5 \mathrm{mg} \mathrm{l}^{-1}\right)$, and EDTA $\left(5 \mathrm{mg} \mathrm{l}^{-1}\right)$.

Medium B contained phosphate buffer (27 mM, pH 7.2), $\mathrm{CaCl}_{2} .2 \mathrm{H}_{2} \mathrm{O} \quad(0.2 \mathrm{mM}), \quad \mathrm{NaCl} \quad(7.56 \mathrm{mM}), \quad \mathrm{MgCl}_{2} \cdot 6 \mathrm{H}_{2} \mathrm{O}$ (0.81 mM), $\mathrm{FeCl}_{2} .4 \mathrm{H}_{2} \mathrm{O}(5.19 \mu \mathrm{M}), \mathrm{HCl}(1.3 \mu \mathrm{l}, 25 \%), \mathrm{ZnCl}_{2}$ $\left(0.07 \mathrm{mg} \mathrm{l}^{-1}\right), \mathrm{MnCl}_{2} .4 \mathrm{H}_{2} \mathrm{O}\left(0.1 \mathrm{mg} \mathrm{l}^{-1}\right), \mathrm{H}_{3} \mathrm{BO}_{3}\left(0.062 \mathrm{mg} \mathrm{l}^{-1}\right)$, $\mathrm{CoCl}_{2} \cdot 6 \mathrm{H}_{2} \mathrm{O} \quad\left(0.19 \mathrm{mg} \mathrm{l}^{-1}\right), \quad \mathrm{CuCl}_{2} .2 \mathrm{H}_{2} \mathrm{O} \quad\left(0.017 \mathrm{mg} \mathrm{l}^{-1}\right)$, $\mathrm{NiCl}_{2} \cdot 6 \mathrm{H}_{2} \mathrm{O}\left(0.024 \mathrm{mg} \mathrm{l}^{-1}\right)$ and $\mathrm{NaMoO}_{4} \cdot 2 \mathrm{H}_{2} \mathrm{O}\left(0.036 \mathrm{mg} \mathrm{l}^{-1}\right)$. These mineral media were supplemented with different carbon and nitrogen sources (see below).

\section{Culture enrichment}

A mixed water and soil sample was collected from the runoff of a Portuguese molinate producing industry. The sample $(10 \%, v / v)$ was incubated in mineral medium $A$ with $400 \mathrm{mg}$ $\mathrm{I}^{-1}$ molinate as carbon and energy source and $\left(\mathrm{NH}_{4}\right)_{2} \mathrm{SO}_{4}$ (3.8 mM), as well as $\mathrm{KNO}_{3}(1.02 \mathrm{mM})$ and $\mathrm{NaNO}_{3}(8.21 \mathrm{mM})$ as additional nitrogen sources. Ten successive transfers at 8day intervals were made to fresh medium $A$ with the same composition ( $5 \%, \mathrm{v} / \mathrm{v}$ of inoculum). This culture (named EC1) was further enriched in medium B using molinate $(750 \mathrm{mg}$ $\mathrm{I}^{-1}$ ) as sole source of carbon and nitrogen, as no additional nitrogen sources were added. Three more successive transfers at 5-day intervals were made to fresh medium B $(5 \%$, $\mathrm{v} / \mathrm{v}$ of inoculum). The final enrichment culture obtained has been named EC2.

Isolation, purification and identification of isolates from the enrichment cultures

In order to identify members of the consortia important for molinate degradation, cultures were serially diluted in sterile saline solution $(\mathrm{NaCl} 0.85 \%$, wt/vol), spread on plate count agar (PCA) and incubated at $30^{\circ} \mathrm{C}$ for 2 days. Individual colonies with distinct morphologies were purified by subculturing on the same medium. Cultivable organisms isolated from enrichment culture EC2 (named ON1 to ON5) were characterized subsequently. The nutritional pattern of the isolates was tested using the Biolog Microplate System, according to manufacturer indications, and identification was done by comparison with the Microlog Gram-negative and Grampositive databases (version 3.0) using the Microlog Distance Coefficient Method (Biolog ${ }^{\mathrm{TM}}$ ). Fatty acid methyl esters (FAMEs) were extracted and analysed as described previously (Kuykendall et al., 1988; Moreira et al., 2000). Identification and quantification of the FAMEs, as well as the 
numerical analysis of the fatty acid profiles, was performed by using the standard MIS Library Generation Software (Microbial ID, Newark, Delaware, USA). Sequencing of the 16S rRNA genes (16S rDNA) of the isolates was determined after PCR amplification using primers $27 \mathrm{f}$ and $1492 \mathrm{r}$ or $1525 \mathrm{r}$ (Lane, 1991). The PCR reactions were performed as described previously (Nogales et al., 2001). The nucleotide sequence of purified PCR products was determined by using the BigDye Teminator Cycle Sequencing Kit and ABI 373 and 377 sequencers (Applied Biosystems), according to the manufacturer's instructions. The sequence data have been submitted to the EMBL database under accession numbers AJ306832 to AJ306836, for isolates ON1 to ON5, respectively. Sequences were aligned and evolutionary distances determined as described by Nogales et al. (2001).

A defined mixed culture, named DC, was constituted by the mixture of equal proportions of the five cultivable isolates (ON1-ON5) purified from enrichment culture EC2.

\section{Culture conditions}

The capability of each individual isolate to grow on molinate or hexamethyleneimine (HMI) as carbon and nitrogen sources was tested in medium B containing $187 \mathrm{mg} \mathrm{l}^{-1}$ (1 mM) to $750 \mathrm{mg} \mathrm{l}^{-1}(4 \mathrm{mM})$ of molinate or $1 \mathrm{mM}$ to $2.5 \mathrm{mM}$ $\mathrm{HMI}$ respectively. The ability of these organisms to use molinate, HMI, ethanethiol $(2.5 \mathrm{mM})$ and diethyl disulphide $(2.5 \mathrm{mM})$ as carbon sources was tested using the same medium supplemented with ammonium sulphate $(3.8 \mathrm{mM})$. Whenever necessary, the media were supplemented with yeast extract $\left(0.2 \mathrm{~g} \mathrm{l}^{-1}\right.$ or $\left.1 \mathrm{~g} \mathrm{l}^{-1}\right)$.

Cultures used for kinetic determinations were grown in screw-capped Erlenmeyer flasks with Teflon-lined caps. Cultures used for headspace analysis were grown in $100 \mathrm{ml}$ PTFE sealed flasks containing $20 \mathrm{ml}$ of medium B. Incubations were made at $30^{\circ} \mathrm{C}, 150$ r.p.m.

The ability of isolates ON1, ON2, ON3 and ON5 to grow on sulphur compounds produced by isolate ON4 was tested. A mixture of isolates ON1, ON2, ON3 and ON5 were grown in medium $B$ supplemented with ammonium sulphate, in a $10-\mathrm{ml}$ vial containing $2.5 \mathrm{ml}$ of medium, placed in the headspace of a culture of isolate ON4 in medium B with $750 \mathrm{mg}$ $\mathrm{I}^{-1}$ molinate. The system was tightly sealed in order to avoid any loss of volatile compounds.

\section{Cell dry weight}

Calibration curves of optical density $\left(\mathrm{OD}_{610 \mathrm{~nm}}\right)$ versus dry weight were obtained by filtering cell suspensions with optical densities ranging from 0.1 to 0.7 through previously weighted glass fibre membranes (Whatman) and drying at $90^{\circ} \mathrm{C}$ until constant weight.

\section{Resting cell assays}

Resting cell assays were performed in phosphate buffer $54 \mathrm{mM}, \mathrm{pH} 7.2$ (PB) with $187 \mathrm{mg} \mathrm{l}^{-1}$ molinate and cell densities corresponding to $1 \mathrm{~g} \mathrm{l}^{-1}$ cells (dry weight). Enrichment culture EC2 and defined mixed culture DC were grown in medium $B$ with $750 \mathrm{mg} \mathrm{l}^{-1}$ molinate and isolates ON1 to ON5 were grown in medium $\mathrm{B}$ with $187 \mathrm{mg} \mathrm{l}^{-1}$ molinate supplemented with yeast extract $\left(1 \mathrm{~g} \mathrm{l}^{-1}\right)$ in axenic culture. The late exponential phase cultures were centrifuged, washed twice with $\mathrm{PB}$, and suspended in $10 \mathrm{ml}$ of PB containing molinate. The suspensions were incubated at $30^{\circ} \mathrm{C}$ and shaken at 150 r.p.m.

\section{Analysis of molinate and degradation products}

Molinate was quantified using a High Performance Liquid Chromatograph (Merck) equipped with an UV-VIS detector (Merck) operating at $210 \mathrm{~nm}$ and a Lichrosphere $5 \mu \mathrm{m}$ RP18 column (Merck). A mixture of methanol:water $(80: 20, \mathrm{v} / \mathrm{v})$ was used as mobile phase at a flow rate of $0.8 \mathrm{ml} \mathrm{min}^{-1}$. Cell free supernatants or dilutions thereof were directly injected in the HPLC.

The presence of molinate sulphoxide, molinate-sulphone, molinate-acid, molinate-alcohol, and 2-oxo-molinate in organic extracts of culture supernatants or liquid phase of resting cell suspensions of isolate ON4 was evaluated using the same mobile phase in a proportion of 50:50 (v/v). The organic extracts were obtained as described previously (Imai and Kuwatsuka, 1982). Briefly, each sample (5 ml) was acidified with concentrated $\mathrm{HCl}(\mathrm{pH} 3)$ and extracted twice with the same volume of $n$-hexane. The $\mathrm{pH}$ of the remaining aqueous phase was adjusted to 10 with $10 \mathrm{~N} \mathrm{NaOH}$, and extracted twice with ethyl ether. The remaining aqueous phase was acidified again with $\mathrm{HCl}(\mathrm{pH} 2)$, and extracted twice with ethyl ether. Each organic extract (acidic hexane, basic ether and acidic ether) was analysed independently.

Solid-phase microextraction (SPME) and gas chromatography was used to analyse molinate degradation products present in the headspace of cultures or resting cells suspensions. The SPME fibre used, 50/30 $\mu \mathrm{m}$ Divinylbenzene/ carboxen/PDMS, was obtained from Supelco (Bellefonte, PA, USA). For each SPME analysis, the fibre was exposed to the headspace of a culture or a resting cells suspension (in $100 \mathrm{ml}$ PTFE sealed vials containing $20 \mathrm{ml}$ of liquid phase, as described above) for $30 \mathrm{~min}$, removed from the vial and inserted into the injection port of the gas chromatograph for $10 \mathrm{~min}$. The fibre was cleaned between each extraction by inserting the fibre in the auxiliary injection port, during $30 \mathrm{~min}$, at $220^{\circ} \mathrm{C}$.

GC analysis were performed on a Hewlett-Packard 5890 (Palo Alto, CA, USA) chromatograph equipped with a flame ionization detector (FID) and CP-WAX 58 (FFAP)-CB $(50 \mathrm{~m} \times 0.32 \mathrm{~mm}, 1.2 \mu \mathrm{m})$ column (Chrompack). The splitless time was $0.5 \mathrm{~min}$. The carrier gas was $\mathrm{H}_{2}$ at a flow rate of $1.2 \mathrm{ml} \mathrm{min}{ }^{-1}$. The FID used hydrogen at $35 \mathrm{ml} \mathrm{min}^{-1}$ and a mixture of nitrogen/oxygen (80/20) at $350 \mathrm{ml} \mathrm{min}^{-1}$. The

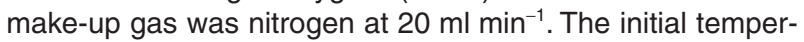
ature was $40^{\circ} \mathrm{C}$. After $1 \mathrm{~min}$ the temperature was increased to $220^{\circ} \mathrm{C}$ at a rate of $2^{\circ} \mathrm{C} \mathrm{min}^{-1}$. The final temperature was held for $30 \mathrm{~min}$. The operating temperatures of injector and detector were $220^{\circ} \mathrm{C}$. Identification of compounds derived from molinate degradation was done by comparison of retention times with those of authentic standards. Degradation products extracted by SPME were also analysed by GC-MS analysis, using a Varian CP-3800 gas chromatograph (USA) equipped with a Varian Saturn 2000 mass selective detector (USA) and a Saturn GC/MS workstation software version 
5.51, as described previously (Silva Ferreira et al., 2003). Identification of chromatographic peaks was achieved by comparisons of mass spectra obtained from the sample with those from authentic standards analysed under the same conditions and by comparing the Kovats indices and the mass spectra present in the NIST 98 MS Library Database.

\section{Analysis of dissolved organic carbon}

The total organic carbon present in culture supernatants (DOC) or dilutions thereof was directly analysed using a Shimadzu 5000 A Total Organic Carbon Analyser (Kyoto, Japan), with high temperature catalytic combustion and $\mathrm{Pt}$ alumina catalyst. For calibration, potassium diphthalate and anhydrous sodium carbonate were used as organic and inorganic standards respectively.

\section{Determination of specific growth rate and molinate specific degradation rate}

Specific growth rates were calculated during the exponential phase of growth. Molinate consumption rate can be expressed as $-\frac{\mathrm{d} S}{\mathrm{~d} t}=\frac{X_{0} \mu}{Y} e^{\mu t}$, where $S$ is the molinate concentration, $\mu$ is the specific biomass growth rate, $Y$ is the observed biological yield and $X_{0}$ is the biomass concentration at $t=0$. Integrating this equation between $t=0$ and $t\left(S=S_{0}\right.$ for $\left.t=0\right)$ we get $S=S_{0}-\frac{X_{0}}{Y}\left(e^{\mu t}-1\right)$. This expression was fitted to the experimental data and the derivative of $S$ with respect to $t$ was computed to obtain the molinate consumption rate $-\frac{\mathrm{d} S}{\mathrm{~d} t}$. The specific molinate degradation rate was calculated as $\frac{1}{X}\left(-\frac{\mathrm{d} S}{\mathrm{~d} t}\right)$ where $X$ is the biomass concentration at time $t$.

\section{Acknowledgements}

We gratefully acknowledge Herbex, Produtos Químicos, S.A. for supplying molinate, Alexandra Diogo and Milton Costa from Departamento de Bioquímica da Faculdade de Ciências e Tecnologia da Universidade de Coimbra for the FAMES analysis by MIDI system, Hans-Adolf Arfmann from Division of Microbiology, GBF-German Research Centre for Biotechnology, Braunschweig for valuable discussions, and Rute Oliveira and Patrícia Correia from LEPAE for technical assistance.

This work was financially supported by Fundação para a Ciência e Tecnologia from Ministério da Ciência e Tecnologia (project PRAXIS/P/BIO/12193/1998 and grants Praxis XXI/ BPD/9936/96, and SFRH/BD/4558/2001).

\section{References}

Arfmann, H.A., Timmis, K.N., and Wittich, R.M. (1997) Mineralization of 4-chlorodibenzofuran by a consortium consisting of Sphingomonas sp. strain RW1 and Burkholderia sp. strain JWS. Appl Environ Microbiol 63: 3458-3462.
Carrasco, J.M., Planta, M., Gomez-Casals, V., and Moragues, V. (1987) Pesticide residues in lake Albufera, Valencia, Spain. J Assoc Off Anal Chem 70: 752-753.

Carrasco, J.M., Sabater, C., Alonso, J.L., Gonzalez, J., Botella, S., Amoros, I., et al. (1992) Molinate decontamination processes in effluent water from rice fields. Sci Total Environ 123/124: 219-232.

Carvalho, M.F., Alves, C.C.T., Ferreira, M.I.M., de Marco, P., and Castro, P.M.L. (2002) Isolation and initial characterization of a bacterial consortium able to mineralize fluorobenzene. Appl Environ Microbiol 68: 102-105.

Chapalamadugu, S., and Chaudhry, G.R. (1991) Hydrolysis of carbaryl by a Pseudomonas sp. and construction of a microbial consortium that completely metabolizes carbaryl. Appl Environ Microbiol 57: 744-750.

Cochran, R.C., Formoli, T.A., Pfeifer, K.F., and Aldous, C.N. (1997) Characterization of risks associated with the use of molinate. Regul Toxicol Pharmacol 25: 146-157.

Daffonchio, D., Baggi, G., Molinari, G.P., Ranalli, G., and Sorlini, C. (1996) Effects of the herbicide molinate on the metabolic activities of a degradative Streptomyces griseus strain. J Environ Sci Health B31: 257-268.

Daffonchio, D., Zanardini, E., Vatta, P., and Sorlini, C. (1999) Cometabolic degradation of thiocarbamate herbicides by Streptomyces sp. strain M2 and effects on the cell metabolism. Annali Di Microbiologia Ed Enzimologia 49: 13-22.

De Souza, M., Newcombe, D., Alvey, S., Crowley, D., Hay, A., Sadowsky, M., and Wackett, L. (1998) Molecular basis of a bacterial consortium: interspecies catabolism of atrazine. Appl Environ Microbiol 64: 178-184.

Ellis, M.K., Richardson, A.G., Foster, J.R., Smith, F.M., Widdowson, P.S., Farnworth, M.J., et al. (1998) The reproductive toxicity of molinate and metabolites to the male rat: effects on testoterone and sperm morphology. Toxicol Appl Pharmacol 151: 22-32.

Feigel, B.J., and Knackmuss, H.-J. (1993) Syntrophic interactions during degradation of 4-aminobenzenesulfonic acid by a two species bacterial culture. Arch Microbiol 159: 124-130.

Golovleva, L.A., Finkelstein, Z.I., Popovich, N.A., and Skryabin, G.K. (1981) Transformation of ordram by microorganisms. Izv Akad Nauk SSSR Series Biol 3: 348-358.

Hay, A., Dees, P., and Sayler, G. (2001) Growth of a bacterial consortium on triclosan. FEMS Microbiol Ecol 36: 105112.

Imai, Y., and Kuwatsuka, S. (1982) Degradation of the herbicide molinate in soils. J Pesticide Sci 7: 487-497.

Imai, Y., and Kuwatsuka, S. (1986a) Characteristics of microflora degrading the herbicide molinate in soil. $J$ Pesticide Sci 11: 57-63.

Imai, Y., and Kuwatsuka, S. (1986b) The mode of metabolism of the herbicide molinate by four strains of microorganisms isolated from soil. $J$ Pesticide Sci 11: 111-117.

Imai, Y., and Kuwatsuka, S. (1986c) Metabolic pathways of the herbicide molinate in four strains of isolated soil microorganisms. J Pesticide Sci 11: 245-251.

Jewell, W.T., and Miller, M.G. (1998) Testicular toxicity in the rat: metabolic activation via sulfoxidation. Toxicol Appl Pharmacol 149: 159-166.

Jewell, W.T., Hess, R.A., and Miller, M.G. (1999) Comparison of human and rat metabolism of molinate in liver 
microsomes and slices. Drug Metab Dispos 27: 842847.

Julli, M., and Krassoi, F.R. (1995) Acute and chronic toxicity of the thiocarbamate herbicide, molinate, to the Cladoceran Moina australiensis Sars. Bull Environ Contam Toxicol 54: 690-694.

Klysheva, A.L., Golovleva, L.A., and Ilyaletdinov, A.N. (1980) Transformation of ordram by microorganisms isolated from soils of Kazakhstan rice paddies. IzV Akad Nauk SSSR Series Biol 4: 29-34.

Kuykendall, L.D., Roy, M.A., O'Neill, J.J., and Devine, T.E. (1988) Fatty acids, antibiotic resistance, and deoxyribonucleic acid homology groups of Bradyrhizobium japonicum. Int J Syst Bacteriol 38: 358-361.

Kyung, K.H., and Fleming, H.P. (1997) Antimicrobial activity of sulfur compounds derived from cabbage. J Food Prot 60: $67-71$.

Lane, D.J. (1991) 16S/23S rRNA sequencing. In Nucleic Acid Techniques in Bacterial Systematics. Stackebrandt, E., and Goodfellow, M. (eds). Chichester: John Wiley \& Sons, pp. 115-175.

Mabury, S.A., Cox, J.S., and Crosby, D.G. (1996) Environmental fate of rice pesticides in California. Rev Environ Contam Toxicol 147: 71-117.

McClung, G., Dick, W.A., and Karns, J. (1994) EPTC degradation by isolated soil microorganisms. J Agric Food Chem 42: 2926-2931.

Molinari, G.P., Sorlini, C., Daffonchio, D., Baggi, G., and Ruffo, L. (1992) Activity and evolution of mixed microbial culture degrading molinate. Sci Total Environ 123/124: 309-323.

Moreira, C., Rainey, F.A., Nobre, M.F., Silva, M.T., and da Costa, M.S. (2000) Tepidimonas ignava gen nov., sp. nov., a new chemolithohererotrophic and slightly thermophilic member of the $\beta$-Proteobacteria. Int $J$ Syst Evol Microbiol 50: 735-742.

Nagy, I., Schoofs, G., Compernolle, F., Proost, P., Vanderleyden, J., and De Mot, R. (1995) Degradation of the thiocarbamate herbicide EPTC (S-Ethyldiproylcarbamothioate) and biosafening by Rhodococcus sp. strain NI86/21 involve an inducible cytochrome P-450 system and aldehyde dehydrogenase. J Bacteriol 177: 676-687.

Nogales, B., Moore, E.R.B., Llobet-Brossa, E., RosselloMora, R., Amann, R., and Timmis, K.N. (2001) Combined use of $16 \mathrm{~S}$ ribosomal DNA and 16S rRNA to study the bacterial community of polychlorinated biphenyl-polluted soil. Appl Environ Microbiol 67: 1874-1884.

Pelz, O., Tesar, M., Wittich, R.M., Moore, E.R.B., Timmis, K.N., and Abraham, W.R. (1999) Towards elucidation of microbial community metabolic pathways: unravelling the network of carbon sharing in a pollutant-degrading bacterial consortium by immunocapture and isotopic ratio mass spectrometry. Environ Microbiol 1: 167-174.

Rainey, F., Weiss, N., Prauser, H., and Stackebrandt, E. (1994) Further evidence for the phylogenetic coherence of actinomycetes with group B-peptidoglycan and evidence for the phylogenetic intermixing of the genera Microbacterium and Aureobacterium as determined by $16 \mathrm{~S}$ rDNA analysis. FEMS Microbiol Lett 118: 135-140.

Rajagopal, B.S., Brahmaprakash, G.P., Reddy, B.R., Singh, U.D., and Sethunathan, N. (1984) Effect and persistence of selected carbamate pesticides in soil. Residue Rev 93: 1-199.

Silva Ferreira, A.C., Hogg, T., and Guedes de Pinho, P. (2003) Key odorants of oxidative spoiled white wines. $J$ Agric Food Chem 51: 1377-1381.

Sipma, J., van Bree, R., Janssen, A.J., Arena, B., Hulshoff, P.L., and Lettinga, G. (2002) Degradation of methanethiol in a continuously operated upflow anaerobic sludgeblanket reactor. Water Environ Res 74: 264-271.

Soderquist, C.J., Bowers, J.B., and Crosby, D.G. (1977) Dissipation of molinate in a rice field. J Agric Food Chem 25: 940-945.

Sorensen, R.S., Ronen, Z., and Aamand, J. (2002) Growth in coculture stimulates metabolism of the phenylurea herbicide isoproturon by Sphingomonas sp. strain SRS2. Appl Environ Microbiol 68: 3478-3485.

Thomas, V.M., and Holt, C.L. (1980) The degradation of $\left[{ }^{14} \mathrm{C}\right]$ molinate in soil under flooded and nonflooded conditions. J Environ Sci Health B15: 475-484.

Tjeerdema, R.S., and Crosby, D.G. (1988) Disposition, biotransformation, and detoxification of molinate (ordram) in whole blood of the common carp (Cyprinus carpio). Pestic Biochem Physiol 31: 24-35.

Tsao, S.M., and Yin, M.C. (2001) In vitro antimicrobial activity of four diallyl sulphides occurring naturally in garlic and Chinese leek oils. J Med Microbiol 50: 646-649.

Zyakun, A.M., Nefedova, M.Y., Baskunov, B.P., and Finkelstein, Z.I. (1983) The new products of ordram microbial degradation. Izv Akad Nauk SSSR Series Biol 1: 126-130. 